\title{
Expansion of S-cycle to Derive a Unique Model for Deciding the Process of Hydrogen Ion Production in Photolysis.
}

\author{
Umasankar Dolai \\ Assistant Teacher, Garhbeta South C.L.R.C., Dwarigeria, Satbankura-721253, District-Paschim Medinipur, \\ West Bengal, India.
}

\begin{abstract}
In this paper, the production of hydrogen $\left(\mathrm{H}^{+}\right)$ions with the formation of oxygen $\left(\mathrm{O}_{2}\right)$ from the splitting of entering water molecules $\left(\mathrm{H}_{2} \mathrm{O}\right)$ is clearly shown according to flash experiment in photolysis. For this purpose, four unstable or metastable intermediate S-states $\left(\left[\mathrm{S}_{0}^{+}\right],\left[\mathrm{S}_{1}^{+}\right],\left[\mathrm{S}_{2}^{+}\right] \&\left[\mathrm{~S}_{3}^{+}\right]\right)$are introduced; which are produced from the four stable $S$-states $\left(S_{0}, S_{1}, S_{2}, \& S_{3}\right)$ respectively via the intermediate $S$-states $\left[Y_{Z}^{o x} S_{n}\right] ; n=0,1,2,3$ respectively after development of reduced tyrosine $\left(Y_{z}\right)$ in $S$-cycle. This attempt can express a unique model of $\mathrm{S}$-cycle over all other introduced schemes about the splitting of water $\left(\mathrm{H}_{2} \mathrm{O}\right)$ to generate electrons $(e)$, hydrogen $\left(\mathrm{H}^{+}\right)$ions and oxygen $\left(\mathrm{O}_{2}\right)$ during photosynthesis.
\end{abstract}

Keywords: Photolysis, Photosystem-II, S-cycle, Flash Experiment, Stable S-states \& Intermediate S-states.

\section{Introduction}

In photosynthesis, the process of splitting of water $\left(\mathrm{H}_{2} \mathrm{O}\right)$ to evolve electrons (e), hydrogen $\left(\mathrm{H}^{+}\right)$ions and oxygen $\left(\mathrm{O}_{2}\right)$ is known as the way of S-state ${ }^{[1]}$ mechanism. ${ }^{[2]}$ Already the formation of oxygen $\left(\mathrm{O}_{2}\right)$ is invented with period-four oscillations of the flash induction; which expresses the four stable $S$-states as $S_{0}, S_{1}$, $\mathrm{S}_{2}$ and $\mathrm{S}_{3} \cdot{ }^{[3]}$ For this purpose, the intermediate $\mathrm{S}$-states $\left(\left[\mathrm{Y}_{\mathrm{Z}}{ }^{\mathrm{ox}} \mathrm{S}_{\mathrm{n}}\right] ; \mathrm{n}=0,1,2,3\right){ }^{[4]}$ are proposed to adjust the transmission of electron (e) from oxygen evolving complex (OEC) towards PS-II by introducing a link between $\mathrm{S}$-states and tyrosine $\mathrm{Z}\left(\mathrm{Y}_{\mathrm{Z}}{ }^{\text {ox }}\right.$; which is known as oxidized tyrosine) as a regulatory mechanism described below

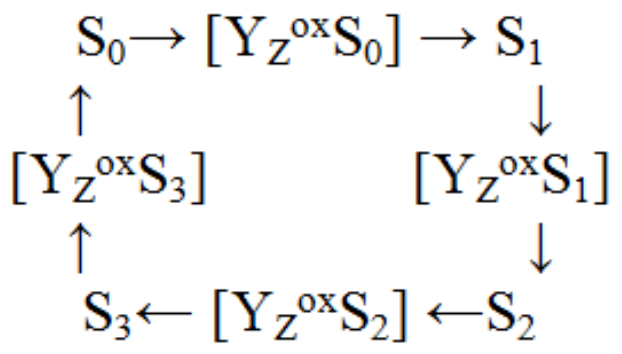

Figure-1

Although the emission and transport of electron (e) from oxygen - evolving complex (OEC) to stabilize $\mathrm{P}_{680}^{+}$as $\mathrm{P}_{680}$ via formation of S-state-tyrosine intermediates by influence of photon (hv) are clearly shown in the above cycle; but the way of production of $\mathrm{H}^{+}$ion is not clearly admitted in the cycle at all. Moreover after formation of reduced tyrosine $\left(\mathrm{Y}_{\mathrm{Z}}\right)$, the developed S-state is somehow unstable by leaving of the electron (e). Rather the final S-state of every oscillation of period - four oscillations is stable to detect the reality of S-state mechanism. So $S_{1}, S_{2}, S_{3}$ and $S_{0}$ states cannot be directly produced from $S_{0}, S_{1}, S_{2}$, and $S_{3}$ states respectively only via $\left[\mathrm{Y}_{Z}{ }^{{ }^{\mathrm{ox}}} \mathrm{S}_{\mathrm{n}}\right] ; \mathrm{n}=0,1,2,3$ intermediate states. Thus there must be exist new intermediate states from which the formation of above production should be happened by releasing $\mathrm{H}+$ ion from the corresponding intermediate S-states; which are metastable.

Actually as electrons (e) are emitted from the S-states $\mathrm{S}_{0}, \mathrm{~S}_{1}, \mathrm{~S}_{2}$ and $\mathrm{S}_{3}$; so the unstable $\mathrm{S}$-states must be $\left[\mathrm{S}_{0}{ }^{+}\right],\left[\mathrm{S}_{1}{ }^{+}\right],\left[\mathrm{S}_{2}{ }^{+}\right]$and $\left[\mathrm{S}_{3}{ }^{+}\right]$in this respect. However these unstable states are stabilized by releasing of $\mathrm{H}^{+}$ions or accepting of electrons. Here first one is more possible than second one for $\left[\mathrm{S}_{0}{ }^{+}\right],\left[\mathrm{S}_{1}{ }^{+}\right] \&\left[\mathrm{~S}_{2}{ }^{+}\right]$state. But to complete the S-cycle in the way of four steps, obviously water $\left(\mathrm{H}_{2} \mathrm{O}\right)$ can react with $\left[\mathrm{S}_{3}^{+}\right]$for returning of $\mathrm{S}_{0}$. Again the evolution of oxygen $\left(\mathrm{O}_{2}\right)$ is detected with maximum on the third and seventh flash. Thus the yielding of oxygen $\left(\mathrm{O}_{2}\right)$ is occurred through the way of formation of $\mathrm{S}_{0}$ from $\left[\mathrm{S}_{3}{ }^{+}\right]$after entering two water molecules $\left(2 \mathrm{H}_{2} \mathrm{O}\right)$. 


\section{Description of S-Cycle}

The four stable S-states in the S-cycle; which are detected from the evolution of oxygen $\left(\mathrm{O}_{2}\right)$ with period - four oscillations of flash induction in photolysis are $S_{0}, S_{1}, S_{2}$ and $S_{3}$. Again the intermediate $S$-state in each stage of oscillation are two types in nature; which are formed in the continuous way. One is tyrosine - Sstate intermediates named as $\left[\mathrm{Y}_{\mathrm{Z}}{ }^{\mathrm{ox}} \mathrm{S}_{0}\right],\left[\mathrm{Y}_{\mathrm{Z}}{ }^{\mathrm{ox}} \mathrm{S}_{1}\right],\left[\mathrm{Y}_{\mathrm{Z}}{ }^{\mathrm{ox}} \mathrm{S}_{2}\right]$ and $\left[\mathrm{Y}_{\mathrm{Z}}{ }^{\mathrm{ox}} \mathrm{S}_{3}\right]$. And the other is metastable $\mathrm{S}$-state intermediates of the corresponding $\mathrm{S}$-states $\left(\mathrm{S}_{0}, \mathrm{~S}_{1}, \mathrm{~S}_{2} \& \mathrm{~S}_{3}\right)$ named as $\left(\mathrm{S}_{0}{ }^{+}\right],\left[\mathrm{S}_{1}{ }^{+}\right],\left[\mathrm{S}_{2}{ }^{+}\right]$and $\left[\mathrm{S}_{3}{ }^{+}\right]$.

Now if the whole cycle is analyzed, then it is expressed into four specific steps written as :

(i) Formation of $\mathrm{S}_{1}$ from $\mathrm{S}_{0}$, via $\left[\mathrm{Y}_{\mathrm{Z}}{ }^{\mathrm{ox}} \mathrm{S}_{0}\right]$ and $\left[\mathrm{S}_{0}{ }^{+}\right]$intermediates,

(ii) Formation of $\mathrm{S}_{2}$ from $\mathrm{S}_{1}$, via $\left[\mathrm{Y}_{\mathrm{Z}}{ }^{\mathrm{ox}} \mathrm{S}_{1}\right]$ and $\left[\mathrm{S}_{1}^{+}\right]$intermediates,

(iii) Formation of $\mathrm{S}_{3}$ from $\mathrm{S}_{2}$, via $\left[\mathrm{Y}_{\mathrm{Z}}{ }^{\mathrm{ox}} \mathrm{S}_{2}\right]$ and $\left[\mathrm{S}_{2}^{+}\right]$intermediates\&

(iv) Formation of $\mathrm{S}_{0}$ from $\mathrm{S}_{3}$, via $\left[\mathrm{Y}_{\mathrm{Z}}{ }^{\mathrm{ox}} \mathrm{S}_{3}\right]$ and $\left[\mathrm{S}_{3}{ }^{+}\right]$intermediates.

The former three steps are quite similar. But there are some differences in forth step with respect to the above three steps. In the upper three steps only the production of $\mathrm{H}^{+}$is occurred from the corresponding unstable states $\left[\mathrm{S}_{\mathrm{n}}{ }^{+}\right] ; \mathrm{n}=0,1,2$ to make the states stable by forming the corresponding stable states $\mathrm{S}_{\mathrm{n}} ; \mathrm{n}=1,2,3$. Where in the forth step, the production of $\mathrm{H}^{+}$with $\mathrm{O}_{2}$ is occurred after entering of two water molecules $\left(2 \mathrm{H}_{2} \mathrm{O}\right)$ into the metastable $\left[\mathrm{S}_{3}{ }^{+}\right]$to form stable state $\mathrm{S}_{0}$. As well as by this formation, the cycle becomes fulfill its period - four oscillations; which is detected by flash-induced oxygen $\left(\mathrm{O}_{2}\right)$ formation in photosynthesis.

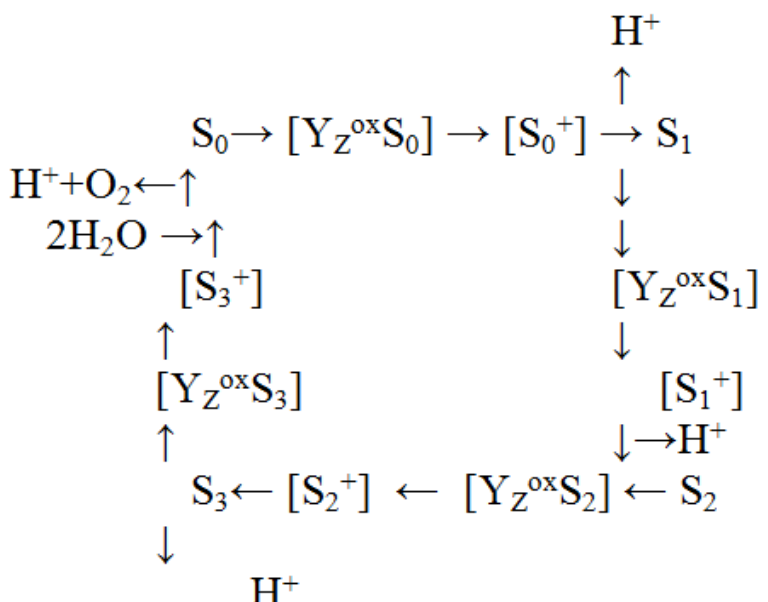

Figure-2

Here the proposed reactions to adjust the production of $\mathrm{H}^{+}$ions with accordance of oxygen $\left(\mathrm{O}_{2}\right)$ formation by entering of water molecules $\left(\mathrm{H}_{2} \mathrm{O}\right)$ in S-cycle are represented in the following way.

(a) $\left[\mathrm{S}_{0}{ }^{+}\right] \rightarrow \mathrm{S}_{1}+\mathrm{H}^{+}$,

(b) $\left[\mathrm{S}_{1}^{+}\right] \rightarrow \mathrm{S}_{2}+\mathrm{H}^{+}$,

(c) $\left[\mathrm{S}_{2}{ }^{+}\right] \rightarrow \mathrm{S}_{3}+\mathrm{H}^{+}$,

(d) $\left[\mathrm{S}_{3}{ }^{+}\right]+2 \mathrm{H}_{2} \mathrm{O} \rightarrow \mathrm{S}_{0}+\mathrm{H}^{+}+\mathrm{O}_{2}$.

\section{Table - I : Description of symbols}

$\mathrm{S}_{0}=$ Initial stable $\mathrm{S}$-state.

$\mathrm{S}_{1}=$ First stable transformed S-state

$\mathrm{S}_{2}=$ Second stable transformed S-state

$\mathrm{S}_{3}=$ Final stable transformed S-state

$\left[\mathrm{S}_{0}^{+}\right]=$Firstunstable transformed S-state

$\left[\mathrm{S}_{1}^{+}\right]=$Second unstable transformed S-state

$\left[\mathrm{S}_{2}{ }^{+}\right]=$Third unstable transformed S-state

$\left[\mathrm{S}_{3}{ }^{+}\right]=$Fourth unstable transformed S-state

\section{Summary}

The mechanism of production of $\mathrm{H}^{+}$ions and formation of oxygen $\left(\mathrm{O}_{2}\right)$ is smoothly described in the above way of S-cycle. Moreover the result of flash experiment is also meaningful with newly proposed cyclic form of the procedure of S-state mechanism side by side. The period-four oscillations of flash-induced oxygen $\left(\mathrm{O}_{2}\right)$ formation can reveal four stable $\mathrm{S}$-states named as $\mathrm{S}_{0}, \mathrm{~S}_{1}, \mathrm{~S}_{2}$ and $\mathrm{S}_{3}$. Again the production of $\mathrm{H}^{+}$ions from four unstable intermediate $S$-states named as $\left[\mathrm{S}_{0}{ }^{+}\right],\left[\mathrm{S}_{1}{ }^{+}\right],\left[\mathrm{S}_{2}{ }^{+}\right]$and $\left[\mathrm{S}_{3}{ }^{+}\right]$is also clearly shown in the new 
proposal of S-cycle. No limitations are found there at all with respect to the conclusion of flash experiment. Finally the complete form of S-cycle is written in this way;

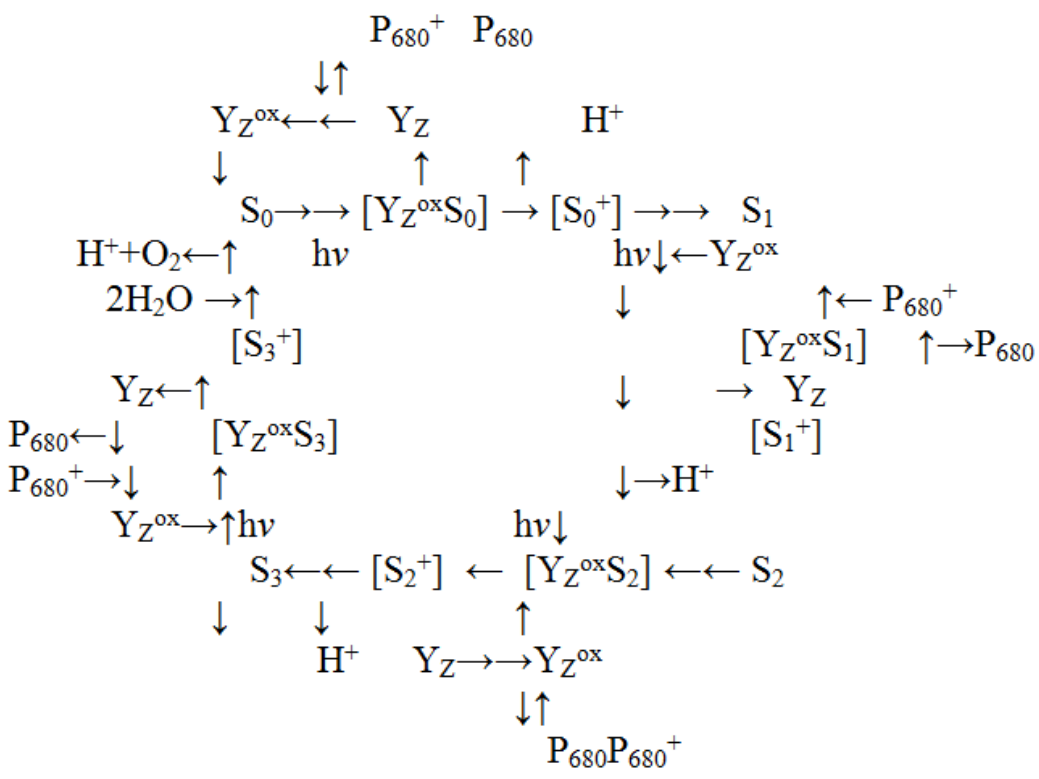

Figure-3

Note added in kinetics. The four periods of S-cycle with intermediates are written below :

I. Period-1: $S_{0}+P_{680}{ }^{+} \rightarrow H^{+}+S_{1}+P_{680},\left(k_{0}\right)$

$\mathrm{S}_{0}+\mathrm{Y}_{\mathrm{Z}}{ }^{\mathrm{ox}} \rightarrow\left[\mathrm{Y}_{\mathrm{Z}}{ }^{\mathrm{ox}} \mathrm{S}_{0}\right],\left(\mathrm{k}_{01}\right) ;\left[\mathrm{Y}_{\mathrm{Z}}{ }^{\mathrm{ox}} \mathrm{S}_{0}\right] \rightarrow \mathrm{Y}_{\mathrm{Z}^{+}}\left[\mathrm{S}_{0}{ }^{+}\right],\left(\mathrm{k}_{02}\right) ; \mathrm{Y}_{\mathrm{Z}^{+}} \mathrm{P}_{680}{ }^{+} \rightarrow \mathrm{Y}_{\mathrm{Z}}{ }^{\mathrm{ox}}+\mathrm{P}_{680},\left(\mathrm{k}_{03}\right) ;\left[\mathrm{S}_{0}{ }^{+}\right] \rightarrow \mathrm{H}^{+}+\mathrm{S}_{1}$, $\left(\mathrm{k}_{04}\right)$; where $\mathrm{k}_{0}=\mathrm{k}_{01} \cdot \mathrm{k}_{02} \cdot \mathrm{k}_{03} \cdot \mathrm{k}_{04}$

II. Period-2: $S_{1}+P_{680}{ }^{+} \rightarrow H^{+}+S_{2}+P_{680},\left(k_{1}\right)$

$\mathrm{S}_{1}+\mathrm{Y}_{\mathrm{Z}}{ }^{\mathrm{ox}} \rightarrow\left[\mathrm{Y}_{\mathrm{Z}}{ }^{\mathrm{ox}} \mathrm{S}_{1}\right],\left(\mathrm{k}_{11}\right) ;\left[\mathrm{Y}_{\mathrm{Z}}{ }^{\mathrm{ox}} \mathrm{S}_{1}\right] \rightarrow \mathrm{Y}_{\mathrm{Z}}+\left[\mathrm{S}_{1}^{+}\right],\left(\mathrm{k}_{12}\right) ; \mathrm{Y}_{\mathrm{Z}}+\mathrm{P}_{680}{ }^{+} \rightarrow \mathrm{Y}_{\mathrm{Z}}{ }^{\mathrm{ox}}+\mathrm{P}_{680},\left(\mathrm{k}_{13}\right) ;\left[\mathrm{S}_{1}^{+}\right] \rightarrow \mathrm{H}^{+}+\mathrm{S}_{2}$, $\left(\mathrm{k}_{14}\right)$; where $\mathrm{k}_{1}=\mathrm{k}_{11} \cdot \mathrm{k}_{12} \cdot \mathrm{k}_{13} \cdot \mathrm{k}_{14}$

III. Period-3: $S_{2}+P_{680}{ }^{+} \rightarrow H^{+}+S_{3}+P_{680},\left(k_{2}\right)$

$\mathrm{S}_{2}+\mathrm{Y}_{\mathrm{Z}}{ }^{\mathrm{ox}} \rightarrow\left[\mathrm{Y}_{\mathrm{Z}}{ }^{\mathrm{ox}} \mathrm{S}_{2}\right],\left(\mathrm{k}_{21}\right) ;\left[\mathrm{Y}_{\mathrm{Z}}{ }^{\mathrm{ox}} \mathrm{S}_{2}\right] \rightarrow \mathrm{Y}_{\mathrm{Z}^{+}}\left[\mathrm{S}_{2}{ }^{+}\right],\left(\mathrm{k}_{22}\right) ; \mathrm{Y}_{\mathrm{Z}^{+}} \mathrm{P}_{680}{ }^{+} \rightarrow \mathrm{Y}_{\mathrm{Z}}{ }^{\mathrm{ox}}+\mathrm{P}_{680},\left(\mathrm{k}_{23}\right) ;\left[\mathrm{S}_{2}^{+}\right] \rightarrow \mathrm{H}^{+}+\mathrm{S}_{3}$, $\left(\mathrm{k}_{24}\right)$; where $\mathrm{k}_{2}=\mathrm{k}_{21} \cdot \mathrm{k}_{22} \cdot \mathrm{k}_{23} \cdot \mathrm{k}_{24}$

IV. Period-4: $\mathrm{S}_{3}+2 \mathrm{H}_{2} \mathrm{O}+\mathrm{P}_{680}{ }^{+} \rightarrow \mathrm{H}^{+}+\mathrm{O}_{2}+\mathrm{S}_{0}+\boldsymbol{P}_{680},\left(k_{3}\right)$

$\mathrm{S}_{3}+\mathrm{Y}_{\mathrm{Z}}{ }^{o x} \rightarrow\left[\mathrm{Y}_{\mathrm{Z}}{ }^{o x} \mathrm{~S}_{3}\right],\left(\mathrm{k}_{31}\right) ;\left[\mathrm{Y}_{\mathrm{Z}}{ }^{o x} \mathrm{~S}_{3}\right] \rightarrow \mathrm{Y}_{\mathrm{Z}^{+}}\left[\mathrm{S}_{3}{ }^{+}\right],\left(\mathrm{k}_{32}\right) ; \mathrm{Y}_{\mathrm{Z}}+\mathrm{P}_{680}{ }^{+} \rightarrow \mathrm{Y}_{\mathrm{Z}}{ }^{o x}+\mathrm{P}_{680},\left(\mathrm{k}_{33}\right) ;\left[\mathrm{S}_{3}{ }^{+}\right]+2 \mathrm{H}_{2} \mathrm{O} \rightarrow$ $\mathrm{H}^{+}+\mathrm{O}_{2}+\mathrm{S}_{0},\left(\mathrm{k}_{34}\right)$; where $\mathrm{k}_{3}=\mathrm{k}_{31} \cdot \mathrm{k}_{32} \cdot \mathrm{k}_{33} \cdot \mathrm{k}_{34}$

Here the constants of the corresponding chemical reactions are given in the brackets.

\section{References}

[1]. Kok, B., B. Forbush, and M. McGloin. 1970 cooperation of charges in photosynthetic $O_{2}$ evolution. I.A Linear four step mechanism. Photochem, Photobios. 11: 457-475.

[2]. Mar, T., and Govindjee. 1972.Kinetic models of oxy evolution in photosynthesis. J. TheorBiol 36:427-446.

[3]. Joliot P. 2003, Period-four oscillations of the flash-induced oxygen formation in photosynthesis, photosyn. Res. 76(1-3) : 65-72. doi : 10.1023/A : 1024946610564. PMID 16228566.

[4]. Jab lonsky J., Lazar D. 2008. Evidence for intermediate S-states as initial phase in the process of oxygen evolving complex oxidation. Biophy. J. 94(7) :2725-36. doi : 10.1529/biophysj. 107.122861. PMC 2267143. OMID 1827865. 